\title{
FREI, Norbert, Vergangenheitspolitik. Die Anfänge der Bundesrepublik und die NS-Vergangenheit
}

Jean Solchany

\section{OpenEdition}

\section{Journals}

Édition électronique

URL : http://journals.openedition.org/ifha/1491

DOI : 10.4000/ifha.1491

ISSN : 2198-8943

Éditeur

IFRA - Institut franco-allemand (sciences historiques et sociales)

Référence électronique

Jean Solchany, «FREI, Norbert, Vergangenheitspolitik. Die Anfänge der Bundesrepublik und die NS-

Vergangenheit », Revue de l'IFHA [En ligne], Date de recension, mis en ligne le 01 janvier 1998, consulté le 22 septembre 2020. URL : http://journals.openedition.org/ifha/1491 ; DOI : https://doi.org/10.4000/ ifha. 1491

Ce document a été généré automatiquement le 22 septembre 2020.

(C)IFHA 


\title{
FREI, Norbert, Vergangenheitspolitik. Die Anfänge der Bundesrepublik und die NS-Vergangenheit
}

\author{
Jean Solchany
}

1 Loin des généralisations aussi hâtives qu'aventureuses que suscite trop souvent encore la question brûlante de la »maîtrise du passé« (Vergangenheitsbewältigung), l'historien munichois N.F. offre dans son dernier ouvrage une reconstitution minutieuse, fondée sur la consultation de très nombreuses archives, de la "politique du passé« (Vergangenheitspolitik) mise en œuvre dans les premières années d'existence de la R.F.A. Par »politique du passé«, l'auteur désigne l'attitude et les prises de décision de la nouvelle classe politique ouest-allemande qui se trouve brusquement confrontée, à partir de 1949, à la difficile gestion des héritages du passé: pour le chancelier Adenauer et plus généralement pour l'ensemble des responsables politiques, qu'ils soient de sensibilité démocrate-chrétienne ou sociale-démocrate, l'une des priorités est en effet de consolider le nouveau régime démocratique. Le gouvernement allemand s'efforce pour ce faire de satisfaire les aspirations de la population non seulement sur le plan économique et social, mais également sur le plan symbolique et mémoriel.

Dans cette perspective, le gouvernement ouest-allemand tente de séduire la clientèle constituée par la masse des Allemands qui se sont plus ou moins gravement compromis sous le nazisme. Il est vrai que le retour au moins partiel à la souveraineté offre la possibilité d'atténuer voire d'annuler la portée des manifestations les plus impopulaires de la politique d'occupation des Alliés: depuis les années 1947-1948, la dénazification et les jugements de criminels nazis par les tribunaux américains, anglais ou français sont en effet perçus par une part grandissante de la population comme autant d'injustices résultant de l'arbitraire de l'occupation. À partir de 1949 et cinq années durant, le gouvernement Adenauer, avec l'assentiment du S.P.D., s'efforce de dissiper ce mécontentement en mettant en œuvre une "politique du passé« visant à réintégrer dans la société allemande comme des citoyens de plein droit la plupart des victimes de l'épuration et de la justice alliée, à l'exception des criminels les plus avérés. En 1949, est 
votée une première loi d'amnistie; en 1950, le Bundestag recommande la fin des procédures de dénazification; en 1952, une loi (das 131er Gesetz) permet la réintégration de très nombreux fonctionnaires - y compris des membres de la Gestapo exclus de la fonction publique par les Alliés; enfin, une seconde loi d'amnistie votée en 1954 parachève ce processus de réhabilitation à grande échelle. Parallèlement à cette intense activité législative, le gouvernement ne cesse de faire pression sur les autorités américaines, anglaises et françaises afin d'obtenir la libération des criminels nazis enfermés dans les prisons allemandes sous contrôlé allié. Le souci de conforter la pusillanimité mémorielle de l'opinion est renforcé par le rôle parfois très actif de groupes de pression comme les Églises ou certaines associations représentant les intérêts des "victimes« de l'épuration ou de la justice alliée. De même, les prises de position des petits partis situés à la droite de l'échiquier politique comme la DP (Deutsche Partei) ou même l'aide droite du F.D.P. ont accentué la pression qui pesait sur les députés C.D.U./C.S.U. et S.P.D. La disculpation massive de la fraction la plus compromise de la population allemande apparaît donc comme la conséquence d'un consensus politique traduisant les sentiments de l'opinion. Pour autant, certaines limites n'ont pas été dépassées: la renaissance de l'extrémisme de droite n'a pas été tolérée, ainsi qu'en témoignent l'interdiction du SRP et le procès du major Remer. Reste que la "politique du passé« a porté gravement atteinte à la détermination de la justice allemande dans la poursuite et la mise en accusation de criminels nazis.

On l'aura compris, l'analyse de N.F. est une contribution significative à l'étude de la mémoire du nazisme. Il est d'autant plus dommage que la présentation des débats et des stratégies qui sont à la base de la Vergangenheitspolitik ne soit pas toujours très claire. 